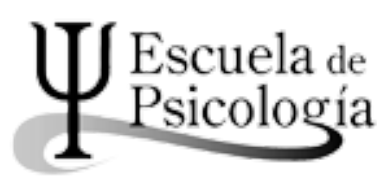

Wímblu, Rev. estudiantes Esc. de psicología, Univ. de Costa Rica. 12 (2): 67-75, 2017 / ISSN: 1659-2107

\title{
El asombro como arché en el corazón iluminado de la psicología, el cine y la vida
}

The wonder as arché in the illuminated heart of psychology, cinema and life

David Selva Aguilar*

Resumen: El artista nos dice Tarkovsky no es más que un fiel servidor de su obra. Asombrado por la belleza de la existencia decide replicar el asombro en la creación. El asombro no solo "está" en el cine, la psicología y la vida sino que sostiene a los tres, que es arché. ¿Qué mueve al artista a crear? Las narrativas de la cinematografía, y las narrativas de la clínica vienen desde la profundidad del alma del sujeto y del cineasta, constructores de símbolos, protagonistas de su propia historia.

Palabras clave: Educación, cine, psicología, alma, filosofía, narrativa.

Resumen: The artist says Tarkovsk is not more tan a servant of his work. Wondered by the beauty of existence decides to reply de wonder of creation. This wonder not only "stays" in film, psychology and life but holds them, is an arché. What moves the artista to create. The film narratives and the narratives of the clinic come from the deepness of the human being, and the filmmaker, symbol constructors, protagonists of their own lifes. Key Words: Education, Film, psychology, soul, philosophy, narrative.

* Universidad de Costa Rica. Costa Rica. Correo electrónico: davselva@gmail.com

Este artículo es fruto de una ponencia presentada en Psinema, espacio de la Escuela de Psicología de la Universidad de Costa Rica para vincular los temas de cine y formación en psicología

Recepción: 28/3/2017 Aceptación: 29/9/2017 
"Cuando es verdadera, cuando nace de la necesidad de decir, la voz humana no hay quien la pare. Si le niegan la boca, ella habla por las manos, o por los ojos, o por los poros o por donde sea." Eduardo Galeano

\section{Preacto (Introducción I): Metaponencia y explicación de los actos narrativos.}

Habría que empezar diciendo que Psinema no es un nombre cualquiera. Sustituye el "kiné" de movimiento en la pareja del "kiné"-"graphos" (en cinematógrafo), es decir, "escritura del movimiento" por un prefijo que viene de alma "psi" ( de psyché-alma). El cine se convertiría aquí en una escritura del alma, con el alma, desde el alma. Luego se verá que quizás no es tan distinto entonces una "escritura" del alma, y una del movimiento, si consideramos el movimiento desde un punto de vista más amplio donde en esta explosión convergente de cine-psicología, no se puede dejar de encontrarnos también con la filosofía, la pedagogía, la espiritualidad.

La palabra "sũwõ" refiere al conjunto de historias que transmiten los hechos del mundo mitológico bribri. Esta incluye no solo el acto de narrar o cantar, sino también la capacidad del narrador de revivir la historia antigua. Sin embargo, "sũwõ" tiene dos significados más en bribri, donde la segunda es "viento". Esto tiene especial relevancia pues Sibö se presenta como el viento que dispersa las semillas (a los bribris), esto habla de la función de identidad que tiene la narrativa, de la función de "ente vitalicio", un acto además de constitución de "lo político". Y la tercer definición de "sũwõ" es todavía más llena de belleza porque es quizás lo que convoca este escrito. "Sũwõ" significa alma. Las historias son el alma de los bribris, y toda su cosmovisión está impregnada por esto. El mismo Sibö ${ }^{1}$ es un contador de historias.

Entonces, discutir el quehacer psinematográfico, el quehacer de la psicología y el quehacer pedagógico interpelan a quienes entran a esa discusión. Agnés Varda habla un poco de esto en el documental "Los Cosechadores y yo". Tanto psicólogos, como cineastas, como artistas, como filósofos, no serían más que cosechadores. La verdad y la belleza ya de por sí "son", preexisten, y estos personajes, el psicólogo, el artista, el filósofo, se convierten en cosechadores, utilizando quizás esa herramienta de la "palabra" y la "historia". La canasta de lo narrativo recoge los tubérculos de las verdades y las bellezas enterrados desde siempre en la tierra de la existencia y los busca enseñar orgulloso al mundo, a través de la palabra de la escritura, de los colores en la pintura, de las melodías en la música, y de la mezcla de estas en el cine. El artista es solo un recolector, no un dios, es solo un señalador de la verdad, no la posee, es albergado dentro de la verdad y la belleza, estas lo desbordan.
Este ensayo es un acto narrativo. Quizá no siga un esquema tradicional aristotélico, pero pretende quien la ejecuta determinarla a través de 8 "actos" y 3 "anti-actos". No hay que dejarse engañar por la palabra "antiactos". Estos son más vivos y son más "actorales" incluso que los actos mismos, sin embargo su nombre deriva de "antistrofa" que explicaré mejor en el acto tercero.

El Acto presentará una disertación aparentemente "teórica" y el antiáctico un apartado "ficcional". Es siempre una situación sustancialmente compleja de definir o delimitar entre lo ficticio y lo "teórico".

\section{Acto: Breve introducción a la comparación entre cine y psicología}

Cuando el autor era pequeño, su mamá le quitaba el volumen a la televisión y jugaban a inventar los diálogos de los personajes. Esto podría parecer un juego inocente; sin embargo esto le enseñó que las historias no están dadas, que se puede seguir construyendo a partir de lo preexistente, que no tenía que sujetarse necesariamente a la narrativa que otros querían dar como única. En esos momentos, aunque no lo sabía, el autor soñó por primera vez con ser guionista. Veinte años después pareciera que todavía lo sigue soñando.

Y no es una cuestión únicamente de escritores ni de cineastas; la Psicología misma está llena de historias, que se pegan en los cuerpos de los que buscan la consulta, historias impregnadas con fuerza en las paredes de cada comunidad que acompañamos, historias en los registros de notas de los niños que no se moldean al modelo educativo que les tocó vivir.

La oscuridad de las salas de cine ha albergado la luz de millones de historias: la de la película, la de los que la ven, la de los que la hicieron y las convergencias entre todas estas. La formación en psicología ilumina asimismo la vida de los estudiantes y profesores, nos interpela, no nos vemos como ajenos a los aprendizajes que se nos presentan; son aprendizajes "transformativos".

Tarkovsky propone que "En el arte, el hombre se apropia de la realidad por su vivencia subjetiva" (1991, p. 62). Y claro que se hace eso en la psicología también, todo está impregnado de subjetividades, hasta la investigación más meticulosamente "objetiva" habla a gritos de lo que se quiere, de las ansiedades que duermen en cada uno, de cada ideal que se existe.

El que se involucra en arte se lo encuentra en cualquier lugar, este lo busca constantemente, explosivamente; no exclusivamente en lo encerrado de museos y galerías, ni siquiera en las salas de los cines, sino en la vida cotidiana, dentro de un bus, en un perro que se acerca, es la belleza eternizada en lo materializado, lo burdo hecho trascendente, no por el objeto en sí, sino por la mirada del que observa. Es la mirada asombrada, casi "de niño", de encontrar en 
lo existente excusas para la fascinación, para el asombro. Heidegger lo expresa hermosamente sobre la filosofía:

Experimentar el asombro en cuanto pathos es el arché de la filosofía. Hay que entender la palabra griega arché en todo su significado. Ésta se refiere a aquello de lo que obtiene su origen cada cosa... Experimentar asombro sostiene la filosofía y la domina de principio a fin.- Pero experimentar asombro es arché, domina del principio hasta el final todos los pasos de la filosofía. El asombro es un pathos. Normalmente traducimos la palabra pathos como pasión, transportación, emoción, pero está estrechamente conectado con paschein que significa sufrir, padecer, aguantar, soportar hasta el final, dejarse llevar por, dejarse determinar por (Heidegger en Petrosino, 2001, p. 20)

Hay un "phatos" asombrado en el artista, que "se deja llevar por, se deja determinar por" el tema artístico, por la vida. Se existen en carne propia la comedia y la tragedia de los personajes. No son una mentira, no son totalmente "ficcionales". Comparten con el escritor, el director o el guionista partes del cuerpo, comparten un sistema nervioso emocionado, se unen ambos en las emociones.

¿Cómo construir una pedagogía del asombro? Una pedagogía de cuerpos que vibran ansiosos por conocer más y no de entes alienados y obligados a los que impulsa la tragedia de la monotonía.

\section{Acto: La forma narrativa como acto moral.}

Contar historias no es un acto inocente. La forma en que se cuente es un acto profundamente moral. A partir de la forma en que se construya una historia se vislumbra una visión ontológica del ser humano y del tiempo. Un ser humano definido por sucesiones lineales de eventos o un ser humano que camina por la vida de manera procesual, donde diferentes procesos se intervienen, se traslapan, se oponen, y dónde la relevancia de los eventos se enmarca dentro de una realidad de simbolización que se da en esta "procesualidad".

Nuestras series de televisión proponen un modelo de ser humano eventualizado, fragmentado en eventos, donde la vida transcurre y lo que la "valida" son exclusivamente momentos. Un ataque repentino de zombies, un nuevo villano, un desastre nuclear, la muerte de un personaje relevante. Frustrante es entonces mirar nuestras vidas, sin eventos determinantes todas las semanas, todos los días, dos veces al día, que solo transcurren dentro de procesos, no todo se resuelve con instantaneidad.

Fuimos ilusos cuando ignoramos al Platón que nos decía que los artistas iban a engañar a las mentes jóvenes haciéndoles creer que era esa la realidad.

\section{Acto: Construir luz desde la oscuridad: Cine como antistrofa}

En el incipt de "Rethorica", Aristóteles abre el texto diciendo que "la retórica es la antistrofa de la dialéctica". Esta palabra "antistrofa" designa el movimiento de réplica, idéntico pero inverso al de la estrofa, con que el coro se desplazaba en las representaciones teatrales. Así que cuando habla de la retórica como esto, designa la importancia fundamental del "modo" en que se transmite una idea en filosofía.

Construyendo una analogía, podríamos ver a las artes como "antistrofas" de los mundos internos de los autores. A pesar de que el cuerpo material del cine es la luz, este se construye desde la oscuridad de los mundos internos, a veces tan densos y veces tan superficiales. De esas oscuridades tan profundas es materializada la belleza del cine, del corazón de Kurosawa, del alma de Fellini, del espíritu de Kubrick; corazones, almas y espíritus angustiados, "ansiosos de lo eterno, de lo incansable", como diría Tarkovsky.

El artista, el cineasta, ¿el psicólogo?, no ve en la oscuridad. Esta oscuridad, la angustia, la eternidad, la incertidumbre, cel no saber?, lo guían. A este no le queda otra que entregarse ciegamente y "dejarse llevar" por el phatos, el asombro.

Sería falso decir que un artista "busca" su tema. El tema va madurando en él como un fruto y le impulsa hacia la configuración. Es como un parto. El poeta nada tiene de lo que pudiera estar orgulloso. No es dueño de la situación, sino su vasallo, su servidor; la creatividad es para él la única forma de vida posible y cada una de sus obras supone un acto al que no se puede negar libremente. (Tarkovsky,1991,p.66)

El artista no es libre. Lo ha encarcelado la belleza y el asombro. Ha transmutado en ella sus angustias. Solo es posible sin embargo, dejarse llevar por el phatos asombrado si se está enamorado primero. Es el amor el que protege al individuo de la oscuridad de la existencia. Quedaría este para siempre en las tinieblas si no se dejara llevar también por el amor, dejándose confundir exclusivamente por el miedo. El amor es iluminativo, es el corazón hablando, son los afectos dirigiendo la conciencia, ¿para qué nos levantaríamos cada día si no hubiera un algo que amamos?. Esto está en el alma del arte, el amor. No un amor como palabra pegajosa y hueca, sino el amor como fuego que enciende tantas las revoluciones, búsquedas incansables por una sociedad más justa, por condiciones biopsicosociales de existencia más sanas para todos lo humanos.

\section{Acto: El conejo de Alicia y el tiempo.}

Pareciera que es esta la sociedad comprimida, la sociedad contenida: en sistemas normativos, ciudades, carpetas digitales y tarritos de almuerzo, corbatas 
enfrascadas en el cuello. Pareciera que es la sociedad de las agendas llenas, donde el amo utilitarismo ha condenado los espacios libres, se ha sobrepuesto el imperio de lo útil. Producir es primordial. Somos entonces, producto que produce.

Esta sociedad comprimida, en buses cargados de gente, en archivos en zip, en fotografías de bajísima calidad, es la sociedad del conejo de Alicia, el conejo que siempre va tarde, una sociedad construida alrededor del tiempo, ser imaginario. En nuestra sociedad de tiempos imaginarios el hombre-máquina, que se ha apartado de si mismo, de sus otros semejantes, cada uno busca sus sistemas de adormecimiento.

El tiempo está a merced de las manos del clínico y del artista. Tarkovsky propone "esculpirlo". El cineasta por ejemplo, deconstruye el tiempo, lo "hackea", no corre la vida su transcurso normal, la edición fragmenta la existencia temporal. El clínico, aunque condicionado, puede "jugar" con el tiempo para buscar proponerle al analizante una vivencia más rica del presente. Desligarse aunque sea un poco de los fantasmas de las ansiedades futuras y preocuparse por lo que sucede en el momento, por el "estar siendo".

Sobre el artista y el tiempo, Borges, nos dice:

Nadie es poeta de ocho a doce y de dos a seis. Quien es poeta, es poeta continuamente, y se ve asaltado por la poesia continuamente...Para la tarea de aue nos corre es un instrumento. todo le ha sido dado como arcilla para que las transmutemos, para que hagamos de las miserables circunstancias de nuestra vida, cosas eternas, que quieren ser eternas (Borges, Agosto de 1977)

¿Cómo podría el artista alejarse del asombro y el arte si esto no le es un hecho contingente sino que está en su substancia? No podría apartarse ni aunque quisiera de la fisura que es dentro de su existencia la tendencia a buscar la belleza, al asombro por las cosas que son.

\section{Acto. Somos historias.}

El asombro lleva a los sujetos a contar historias, de la vida cotidiana, de sus vidas carentes de zombies y superhéroes voladores. Estas historias, que es lo que son, palabras transformadas en persona, definen a los sujetos. Es muy peligroso entonces jugar con las historias de los demás, construir mononarrativas de comunidades, países, continentes. Las mononarrativas, generalmente basadas en estereotipos se materializan en acciones concretas en la vida de individuos concretos. Mononarrativizar La Carpio como una comunidad violenta, conlleva a que muchos jóvenes de la comunidad no puedan acceder a trabajo, mononarrativizar a las personas con orientación homosexual como pervertidos sexuales es una forma de alienar a miles de personas con esta orientación sexual, mononarrativizar a los católicos como fundamentalistas es una forma de violencia simbólica de caricaturización contra personas que han optado por una determinada opción de

fe. El papel del asombro es fundamental aquí, su discusión no está exenta.

Freire propone:

No hay diálogo si no hay un profundo amor al mundo y a los hombres. No es posible la pronunciación del mundo, que es un acto de creación y recreación, si no existe amor que lo infunda. Siendo el amor fundamento del diálogo, es también diálogo. El amor es un acto de valentía, nunca de temor; el amor es compromiso con los hombres. Dondequiera exista un hombre oprimido, el acto de amor radica en comprometerse con su causa. La causa de su liberación. Este compromiso, por su carácter amoroso, es dialógica. (Freire, 1970, p.72)

El ejercicio de la narrativa y de la psicología estarían profundamente marcados por el asombro en el otro, por las historias del que es, como yo, una construcción de historias.

\section{Acto. El arte y el ser: Una suerte de trabalenguas filosófico- psicológico-cinematográfico que en primera instancia será un avión arriba pero después intentará aterrizar.}

Todo cambia dice Heráclito de Éfeso, no puede un hombre cruzar dos veces el mismo río, pues ya no será el río el mismo ni el hombre será el mismo. El cambio físico del río que fluye, y el cambio metafísico del hombre, que no es ontológicamente el mismo. Lo único que no cambia es el cambio. El cambio es motor de movimiento que no se mueve, es el cambiador incambiante.Todo arte, toda búsqueda de la verdad,y toda pedagogía están en la ubicuidad del cambio. El cambio es en primera instancia y después todas estas que se ubican dentro de él. El cambio no está en ningún lugar ni tiempo sino que todos los sujetos están sumergidos en el cambio que los desborda. Pareciera incluso que la teoría de la relatividad de Einstein, o de la invariabilidad de la luz está dentro del cine. No solo como material físico sino como esa luz metafísica invariable que se usa en el cine y las artes y que no es sino del Ser, es el thelos de todo: la belleza, la sabiduría, la verdad en si, en su estado de sujetos incambiables pero cambiadores. La pregunta se orientaría entonces en el ¿por qué el arte y el conocimiento son y no más bien no son?. Es que esa pareciera ser una de las preguntas sustanciales: ¿porqué el ser y no más bien la nada?, como diría Heidegger. El humano entonces, se encuentra ante la profundidad del universo que es, y queda atónito, se siente pequeño ante el espacio y el tiempo que le habitan. 
Sin embargo en un segundo momento se encuentra con que el espacio y el tiempo, en nuestro caso un universo de miles de millones de años luz están en constante cambio y se da cuenta de que están sujetos al "ser", el cual aun en ausencia de ambos transforma metaespacialmente y metatemporalmente y no le queda al sujeto más que el asombro.

Algunos, quizás intentando desviar este asombro optaran por decir "no tiene ningún propósito el universo". Bastante que se equivocan. Cualquiera podría realizar de la orientación direccional de los objetos que se mueven. Lo que "es", no solo se mueve, sino que se mueve "hacia", hay direccionalidad, hay propósito. El ser tiene propósito. Esto es lo paradójico y complejo de la nada, que al no moverse tampoco se confunde con el cambio incambiante. Es la pregunta devastadora del joven Hamlet ante el misterio de la muerte:¿Ser o no ser?

Podría suceder que esta realización de "ser" sea también un acto traumante. El sujeto podría querer volver al oscuro útero materno, donde está protegido de la pregunta. Podría querer regresar a la caverna del mito platónico, fría, pero segura, ante el encandilante sol de lo que "es".

Aterrizando un poco, se intentará conjeturar sobre el rol de esto, el "ser" en el arte y la psicología:

¿Y qué tiene que ver esto con el arte? Entonces, el artista mimetiza el acto creativo del ser. El ser manifiesta que es amor en tanto hace que los seres sean y el artista manifiesta que ama en tanto sus obras están siendo más que no estar siendo. Crear al artista y construir arte son actos amorosos en tanto dan existencia. Existir es un acto de reparación después del asombro de ser, existir entonces es una obra de arte. En esta instancia tiene más sentido cuando Tarkovsky nos habla del "ansia de lo eterno" del artista.

Así como el ser es transformador, el artista encuentra su libertad en el sometimiento a su existencia creadora y asombrada. Paradójicamente es en el encuentro con este encadenamiento que encuentra su total liberación.

El maestro Tarkovsky nos preguntaría:

¿Tal vez el significado de toda actividad humana yace en la conciencia artística, en el acto desinteresado y sin objetivo de crear? ¿Tal vez nuestra capacidad de crear es evidencia de que nosotros fuimos creados en la imagen y semejanza de Dios?.(1990)

¿Y qué tiene que ver con la psicología? La psicología sería de alguna manera un estudio de entes que son y son conscientes de que son, $y$ en algún momento de su transcurrir espacio-temporal se preguntan sobre la orientación de su ser, "¿qué debo hacer con este que soy?" Y el terapeuta, es ese otro que reconoce también su ser pero realizándose de que el otro también es y labora desde ahí.

\section{Acto. Conclusión a modo de palimpsesto.}

Es una compleja situación ejecutar conclusiones, como si fuera posible cerrar los textos y abandonarlos. Terrible engaño sería esto, creer que el libro se acaba en el último capítulo. Se podría pensar más bien que cada texto se adhiere a la continuidad de la vida. Cada texto queda abierto como un palimpsesto sobre el que se escriben numerosas reflexiones.

El todo preexiste al arte, este de alguna manera viene como ente degradado a encontrarse con el sujeto. A modo de falsa conclusión que es más bien una apertura, las preguntas tendría que orientarse hacia los asombros ¿cuál es el papel del asombro en mi cotidiano? ¿cuál es el papel de asombro en el arte? ¿cuál es el papel del asombro en la psicología? ¿porqué el asombro y no más bien la nada?

\section{Notas}

1. Deidad principal de los bribris.

\section{Referencias}

Borges, J. (1977). Conferencia dictada por Jorge Luis Borges el 3 de agosto de 1977 en el teatro Coliseo de Buenos Aires. Recuperada de http://borgestodoelanio. blogspot.com.ar/2014/01/jorge-luis-borges-en-su-voz-la-ceguera.html.

Freire, P. (1970). Pedagogía del Oprimido. Siglo Veintiuno Editores. Buenos Aires, Argentina

Heidegger, M. (1950). ¿Qué es esto, la filosofía?. Buenos Aires: Sur.

Petrosino, S. (2001). El Asombro. Traducción de Belén Cabello. Ediciones Encuentro S.A. Madrid.

Tarkovski, A. (1991). Esculpir el tiempo: Reflexiones sobre el arte, la estética y la poética del cine. Madrid, Rialp.

\section{c) (i) (2)}

Esta obra está bajo una licencia de Creative Commons Reconocimiento - NoComercial - CompartirIgual (by-nc-sa) 